\title{
O impacto do trabalho rotativo e noturno no contexto do câncer de mama e de próstata: uma revisão sistemática
}

The impact of rotary and night work in the context of breast and prostate cancer: a systematic review

El impacto del trabajo rotativo y nocturno en el contexto del cáncer de mama y próstata: una revisión sistemática

Leonardo Fontineles de Lima ORCID: https://orcid.org/0000-0001-6817-3811 Universidade Federal do Delta do Parnaíba, Brasil

E-mail: leonardofontineles@ hotmail.com

Dayla Cristine Dutra Carvalho ORCID: https://orcid.org/0000-0001-5141-9328 Universidade Federal do Delta do Parnaíba, Brasil E-mail: daylacristine@hotmail.com

Ana Indygriani Rodrigues ORCID: https://orcid.org/0000-0003-4070-4048 Universidade Federal do Delta do Parnaíba, Brasil E-mail: Indygliane@gmail.com

Valécia Natália Carvalho da Silva ORCID: https://orcid.org/0000-0001-5739-0722 Universidade Federal do Delta do Parnaíba, Brasil E-mail: valeciacs@gmail.com

Hélio Mateus Silva Nascimento ORCID: https://orcid.org/0000-0003-1551-8139 Universidade Federal do Delta do Parnaíba, Brasil E-mail: helio_mateus_@hotmail.com

John Arlley Sousa Pinho de Lira ORCID: https://orcid.org/0000-0001-6565-6260 Universidade Federal do Delta do Parnaíba, Brasil E-mail: arlley_pinho@hotmail.com

Francisco Alex da Rocha Coelho ORCID: https://orcid.org/0000-0002-3308-375X Universidade Federal do Delta do Parnaíba, Brasil E-mail: alex123rocha@hotmail.com

Paulo Roberto Carneiro Gomes

ORCID: https://orcid.org/0000-0002-2911-7785

Universidade Federal do Delta do Parnaíba, Brasil E-mail: paulo.c.gomes1@outlook.com

Tom Ravelly Mesquita Costa

ORCID: https://orcid.org/0000-0002-3092-6192

Universidade Federal do Delta do Parnaíba, Brasil E-mail: tomravely20@hotmail.com

Hoanna Izabely Rego Castro ORCID: https://orcid.org/0000-0001-5646-4902 Universidade Federal do Delta do Parnaíba, Brasil E-mail: hoannacastro@gmail.com

Even Herlany Pereira Alves

ORCID: https://orcid.org/0000-0001-7566-1282

Universidade Federal do Delta do Parnaíba, Brasil

E-mail: even.herlany@gmail.com

Antonio Thomaz de Oliveira

ORCID: https://orcid.org/0000-0003-0277-6833

Universidade Federal do Delta do Parnaíba, Brasil E-mail: thomaz.o@ufpi.edu.br

\section{Resumo}

Este trabalho tem o objetivo de verificar na literatura a relação entre o câncer e ao trabalho noturno e rotativo. Para isso, foi realizada uma pesquisa utilizando as bases de dados PUB MED, WEB OF SCIENCE, SCOPUS e LILACS, 
onde foram encontrados 649 estudos nos últimos 5 anos relacionados ao tema. Após passarem por alguns processos de exclusão, restaram apenas 23 estudos que correspondiam aos critérios da pesquisa. No presente trabalho foram analisados estudos de coorte, estudos de caso controle, estudos transversais e estudos experimentais, 15 desses estudos se tratavam de câncer de mama, 6 de câncer de próstata e 2 de ambos os cânceres. Foram destacados os enfermeiros como público principal das pesquisas. De acordo com os resultados desta revisão, foi sugerido que o trabalho noturno com interrupção do ritmo circadiano pode afetar e diminuir a síntese de melatonina, o que torna um fato preocupante visto que, níveis baixos de melatonina foi intimamente relacionada tanto ao câncer de mama quanto de próstata, e também foi classificada com importante função antitumoral. Outros possíveis fatores relacionados ao trabalho noturno e o câncer de mama é o encurtamento dos telômeros e hábitos de risco durante o período noturno. Diante dos possíveis riscos atribuídos a estes dois tipos cânceres, acredita-se que a cronoterapia e a suplementação a base melatonina seriam medidas importantes no processo de prevenção.

Palavras-chave: Câncer de mama; Câncer de próstata; Trabalho noturno; Ritmo circadiano.

\begin{abstract}
This work aims to verify in the literature the relationship between cancer and night and shift work. For this, a search was carried out using the PUB MED, WEB OF SCIENCE, SCOPUS and LILACS databases, where 649 studies were found in the last 5 years related to the subject. After going through some exclusion processes, there were only 23 studies that matched the research criteria. In the present work, cohort studies, case-control studies, cross-sectional studies and experimental studies were analyzed, 15 of these studies were about breast cancer, 6 about prostate cancer and 2 about both cancers. Nurses were highlighted as the main research audience. According to the results of this review, it was suggested that night work with interruption of the circadian rhythm may affect and decrease melatonin synthesis, which makes it a worrying fact since low levels of melatonin were closely related to both breast cancer and prostate, and was also classified as having an important antitumor function. Other possible factors related to night work and breast cancer are telomere shortening and risky habits during the night shift. Given the possible risks attributed to these two types of cancer, it is believed that chronotherapy and melatonin-based supplementation would be important measures in the prevention process.
\end{abstract}

Keywords: Breast cancer; Prostate cancer; Night work; Circadian rhythm.

\title{
Resumen
}

Este trabajo tiene como objetivo verificar en la literatura la relación entre el cáncer y el trabajo nocturno y por turnos. Para ello, se realizó una búsqueda utilizando las bases de datos PUB MED, WEB OF SCIENCE, SCOPUS y LILACS, donde se encontraron 649 estudios en los últimos 5 años relacionados con el tema. Después de pasar por algunos procesos de exclusión, solo hubo 23 estudios que cumplieron con los criterios de investigación. En el presente trabajo se analizaron estudios de cohortes, estudios de casos y controles, estudios transversales y estudios experimentales, 15 de estos estudios fueron sobre cáncer de mama, 6 sobre cáncer de próstata y 2 sobre ambos cánceres. Se destacó a las enfermeras como la principal audiencia de investigación. De acuerdo con los resultados de esta revisión, se sugirió que el trabajo nocturno con interrupción del ritmo circadiano puede afectar y disminuir la síntesis de melatonina, lo que lo convierte en un dato preocupante ya que los niveles bajos de melatonina estaban estrechamente relacionados tanto con el cáncer de mama como con el de próstata, y fue también se clasifica como que tiene una función antitumoral importante. Otros posibles factores relacionados con el trabajo nocturno y el cáncer de mama son el acortamiento de los telómeros y los hábitos de riesgo durante el turno de noche. Dados los posibles riesgos atribuidos a estos dos tipos de cáncer, se cree que la cronoterapia y la suplementación a base de melatonina serían medidas importantes en el proceso de prevención.

Palabras clave: Cáncer de mama; Cáncer de próstata; Trabajo nocturno; Ritmo circadiano.

\section{Introdução}

Nos últimos anos o câncer tem se tornado uma preocupação a nível global. A etiologia da doença é complexa e envolve vários fatores de risco biológicos e de fatores ambientais, estilo de vida, fatores genéticos hereditários, como mutações de alto risco nos genes de câncer, além disso, existem fatores ocupacionais. A Agência Internacional de pesquisa em câncer classificou em 2007 o trabalho por turnos, que envolve perturbações no ritmo circadiano, como possivelmente carcinogênico. Desde então tem surgido inúmeras pesquisas que buscam evidências entre a relação do trabalho noturno e câncer (Behrens et al., 2017).

O sistema circadiano é responsável por regular diversos processos fisiológicos do corpo humano. Nesta revisão sistemática foram encontradas associações significativas entre trabalho noturno que envolve ruptura do ritmo circadiano e o câncer de mama e câncer de próstata (Behrens et al., 2017; De castro et al., 2018). No entanto foram encontrados artigos que 
discordam dessa ideia, justificando-se da ausência de achados relevantes (Hammer et al., 2015; Li et al., 2015; Åkerstedt et al., 2017; Fritschi et al., 2018; Jones et al., 2019; Pham et al., 2019).

Os mecanismos para a associação entre trabalho noturno e aumento do risco de câncer ainda são amplamente desconhecidos, acredita-se que o trabalho noturno com interrupção do ritmo circadiano e com carga horária extensa a longo prazo está intimamente relacionado a distúrbios metabólicos que podem ser considerados fatores de risco para o desenvolvimento do câncer de mama e câncer de próstata. Ressalta-se que a desregulação do ritmo circadiano, afeta diretamente a expressão dos genes do relógio (do inglês clock genes), onde estes por sua vez constatam-se plausivelmente relacionados a síntese de melatonina (De castro et al., 2018; Pham et al., 2019).

Estudos apontam que a melatonina produz um potente efeito anticâncer circadiano, sugere-se que o trabalho noturno está relacionado a diminuição dos níveis de melatonina, o que acaba por inibir sua função de supressão tumoral em diversos tecidos (De castro et al., 2018). Propôs-se que o encurtamento dos telômeros possa ser outro possível fator contribuinte para o surgimento do câncer de mama relacionado ao trabalho por turnos que envolvem perturbações no ritmo circadiano a longo prazo (>20 anos) (Samulin et al., 2017). Assim como o câncer de próstata, inclusive com pior prognóstico também foi relacionado a trabalho noturno com longas horas de trabalho consecutivas (Papantoniou et al., 2015).

Diante disso, sabendo-se que existem relações entre disfunções circadianas e trabalho noturno, o que pode promover disfunções metabólicas, é importante entender que trabalhadores que estão expostos a esse transtorno tem uma maior tendência a desenvolver alterações metabólicas. Neste estudo foram encontradas associações significativas entre o trabalho noturno e o câncer de mama e de próstata. Ao longo desta revisão as mesmas foram descritas e analisadas criticamente explorando seus efeitos, visto que os mesmos são uns dos principais tipos de cânceres a nível mundial, o que justifica a importância do presente trabalho. O objetivo deste estudo, foi investigar o papel do trabalho noturno e rotativo no câncer de mama e câncer de próstata por meio de bases de dados na literatura científica.

\section{Metodologia}

Foi realizada uma busca na base de dados Prospective Register of Systematic Review (PROSPERO) com o objetivo de verificar se está registrado o andamento de uma revisão com a associação de descritores comuns ao nosso estudo: Shift Work Schedule OR shift work OR shift workers OR night work) AND (Prostatic Neoplasm OR Prostate Cancer OR Breast Neoplasm OR Breast Cancer. Não foi encontrado nenhum registro com objetivo igual ao presente trabalho até a data 05 de julho de 2019. As bases de dados escolhidas para o presente trabalho foram: PubMed/Medline (Medical Literature Analysis and Retrievel System Online), Web of Science, Scopus (pertencente a editora Elsevier) e LILACS (Literatura Latino-Americana e do Caribe em Ciências da Saúde). Para a construção do desenho da revisão sistemática, foi utilizado o protocolo PRISMA (Preferred Reporting Items for Systematic Reviews and Meta-Analysis), seguindo o checklist do PRISMA-P (http://prismastatement.org/documents/PRISMA-P-checklist.pdf).

No PubMed, para o trabalho noturno ou por turnos, foi utilizado o MeSH term "Shift Work Schedule" e, para aumentar a abrangência da pesquisa, foram incluídos os entry terms "shift work", "shift workers" e "night work". Para a depressão, foram utilizados os MeSH terms "Prostatic Neoplasm" OR "Prostate Cancer " OR " Breast Neoplasm disorder" OR "Breast Cancer". Foram utilizados os operadores Booleanos "AND" e "OR" entre os termos. Foi utilizado o filtro de data de 01 de janeiro de 2014 a 01 de julho de 2019. E para encontrar apenas estudos com humanos, foi utilizado o filtro "Humans". Nesse banco de dados, com o uso dos descritores e os filtros supracitados, foram encontrados 148 artigos.

Foi realizada uma busca no Web of Science Core Collection utilizando o seguinte descritor [TS=(( Prostatic Neoplasm OR Prostate Cancer OR Breast Neoplasm OR Breast Cancer) AND (Shift Work Schedule OR shift work* OR night work*))] com o intervalo de tempo "últimos 5 anos", na busca avançada, selecionando apenas artigos. Nesse banco de dados foram 
encontrados 387 artigos. Já na base de dados Scopus, foi realizada uma pesquisa com os seguintes descritores [(“Prostatic Neoplasm” OR "Prostate Cancer" OR “Breast Neoplasm” OR “Breast Cancer”) AND ("Shift Work Schedule” OR "shift work” OR “shift workers" OR “night work”)], com limite de ano de 2014 á 2019, tipo de documentos (artigos) e tipo de acesso. No qual foram encontrados 111 artigos. Para o LILACS foram utilizados descritores de saúde (DeCs): Prostate Cancer OR Breast Cancer and shift work. Foram encontrados 7 resultados, porém apenas 3 artigos que se incluíam no critério de filtro de tempo 2014 a 2019.

Assim, foi obtido um total de 649 artigos, onde os títulos, os bancos de dados, os anos e os resumos foram organizados em planilhas no Excel. Os artigos foram primeiramente excluídos por repetitividade e segundamente foram analisados quanto à leitura do título e resumo, que foi usado como critério de exclusão por título e resumos, como consta no esquema a seguir.

Os critérios de exclusão considerados foram:

1. Natureza do artigo. Apenas artigos completos e de natureza experimental/observacional com humanos (triagens clínicas, caso-controle, estudos de coorte prospectivos e retrospectivos) foram incluídos. Não foram incluídas na revisão, revisões sistemáticas, meta-análises, estudos de caso, short communications, teorias e outros artigos de natureza não experimental/observacional com seres humanos.

2. O artigo não trata da população de interesse: trabalhadores por turno e/ou noturnos.

3. O artigo não trata da condição de interesse: câncer de mama e câncer de próstata.

4. O artigo não faz associação entre a população de interesse e a condição.

5. Outros

Depois da análise desses critérios de exclusão restaram nessa pesquisa apenas 106 artigos que se encaixaram com o objetivo proposto. Após a leitura completa dos 106 artigos restantes, ficaram nesse estudo apenas 23 artigos para o desenvolvimento da pesquisa, como é demonstrado na Figura 1.

Figura 1: Representação esquemática da metodologia.

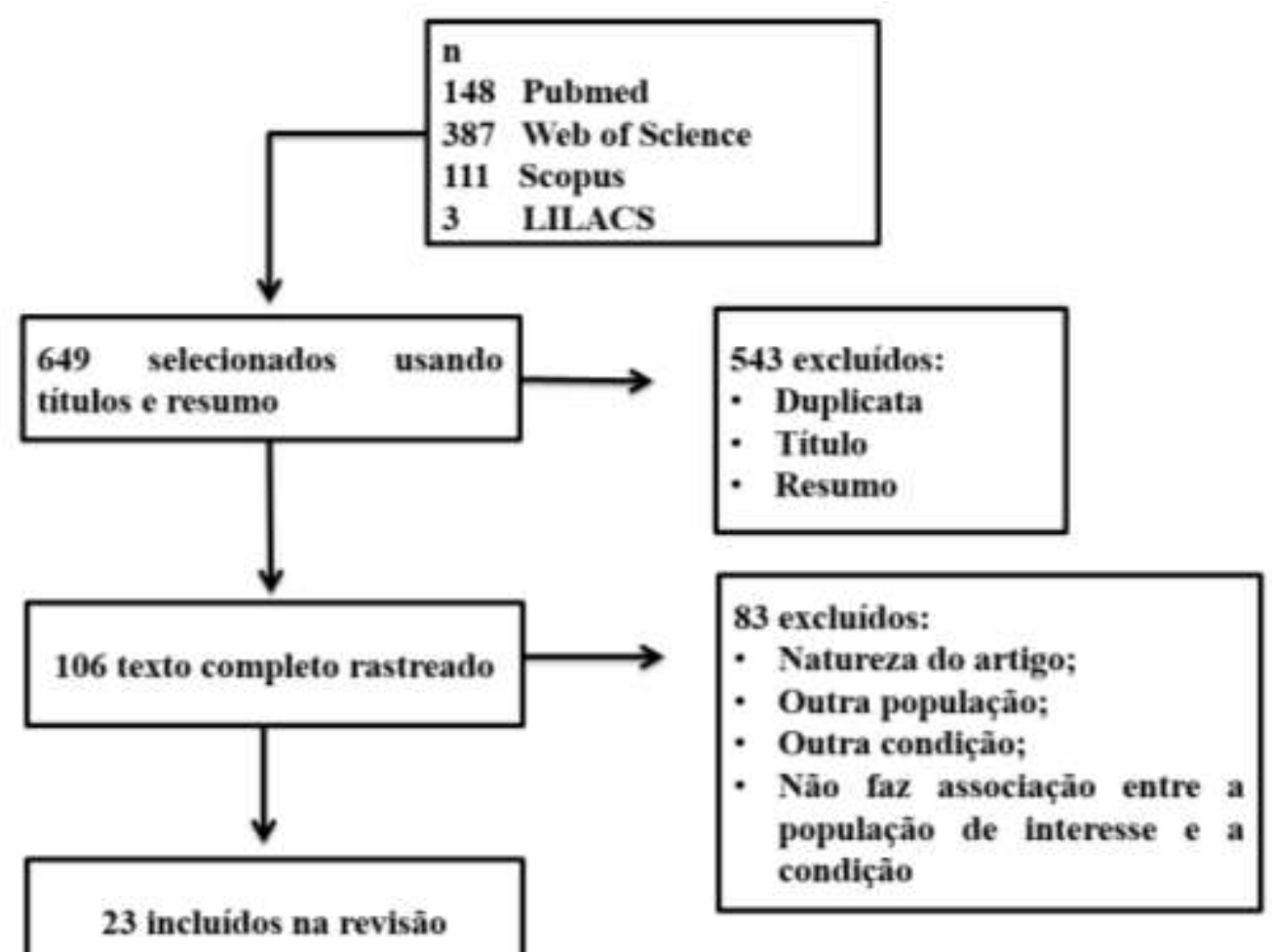

Fonte: Autores. 


\section{Resultados}

Os artigos com relação entre a associação do trabalho noturno e rotativo com câncer de mama e de próstata presente nesse estudo estão descritos na Tabela 1, com os achados dos números populacionais, o tipo de pesquisa, a atuação dos trabalhadores, objetivo e os principais resultados.

Tabela 1. Dados descritivos dos 23 estudos selecionadas para a composição da presente revisão sistemática.

\begin{tabular}{|c|c|c|c|c|c|c|}
\hline $\begin{array}{c}\text { Autores e } \\
\text { ano }\end{array}$ & $\begin{array}{l}\text { Número } \\
\text { amostral }\end{array}$ & $\begin{array}{l}\text { Tipo de } \\
\text { pesquisa }\end{array}$ & $\begin{array}{l}\text { Condição } \\
\text { de } \\
\text { interesse }\end{array}$ & População & Objetivo & Principais resultados \\
\hline $\begin{array}{l}\text { (Behrens et } \\
\text { al., 2017) }\end{array}$ & 1.757 & $\begin{array}{l}\text { Estudo de } \\
\text { coorte } \\
\text { prospectivo }\end{array}$ & $\begin{array}{c}\text { Câncer de } \\
\text { próstata }\end{array}$ & $\begin{array}{c}\text { Trabalhadores } \\
\text { noturnos da } \\
\text { Alemanha }\end{array}$ & $\begin{array}{c}\text { Associar o trabalho } \\
\text { noturno ou por turno com a } \\
\text { incidência de câncer de } \\
\text { próstata. }\end{array}$ & $\begin{array}{l}\text { Aumento da taxa de risco em } \\
\text { duas vezes para câncer de } \\
\text { próstata entre trabalhadores } \\
\text { noturnos em ralação aos demais. }\end{array}$ \\
\hline $\begin{array}{l}\text { (Samulin et } \\
\text { al., 2017) }\end{array}$ & 1.182 & $\begin{array}{c}\text { Estudo de } \\
\text { caso controle }\end{array}$ & $\begin{array}{c}\text { Câncer de } \\
\text { mama }\end{array}$ & $\begin{array}{l}\text { Enfermeiras } \\
\text { na Noruega }\end{array}$ & $\begin{array}{l}\text { Investigar a contribuição } \\
\text { dos extensos horários de } \\
\text { trabalho noturno como } \\
\text { fator responsável pelo } \\
\text { encurtamento dos } \\
\text { telômeros relacionado no } \\
\text { risco de câncer de mama. }\end{array}$ & $\begin{array}{l}\text { Encurtamento de telômeros foi } \\
\text { associado ao aumento do risco de } \\
\text { câncer de mama em trabalhadores } \\
\text { com longos períodos de turnos } \\
\text { noturnos consecutivos. }\end{array}$ \\
\hline $\begin{array}{c}\text { (Åkerstedt et } \\
\text { al., 2017) }\end{array}$ & 12.322 & $\begin{array}{l}\text { Estudo de } \\
\text { coorte }\end{array}$ & $\begin{array}{l}\text { Câncer de } \\
\text { próstata }\end{array}$ & $\begin{array}{l}\text { Trabalhadores } \\
\text { noturnos na } \\
\text { Suécia }\end{array}$ & $\begin{array}{c}\text { Investigar a relação } \\
\text { prospectiva entre número } \\
\text { de anos de trabalho } \\
\text { noturno e câncer de } \\
\text { próstata. }\end{array}$ & $\begin{array}{l}\text { Não mostrou associação } \\
\text { significativa entre trabalho } \\
\text { noturno e câncer de próstata. }\end{array}$ \\
\hline $\begin{array}{l}\text { (Vistisen et } \\
\text { al., 2017) }\end{array}$ & 155.540 & $\begin{array}{l}\text { Estudo de } \\
\text { coorte }\end{array}$ & $\begin{array}{c}\text { Câncer de } \\
\text { mama }\end{array}$ & $\begin{array}{l}\text { Trabalhadores } \\
\text { públicos na } \\
\text { Dinamarca }\end{array}$ & $\begin{array}{c}\text { Examinar se o trabalho no } \\
\text { turno da noite é um fator } \\
\text { de risco para o câncer de } \\
\text { mama. }\end{array}$ & $\begin{array}{l}\text { A redução da produção noturna } \\
\text { de melatonina pineal é sugerida } \\
\text { como um elemento central dos } \\
\text { mecanismos que ligam o trabalho } \\
\text { no turno da noite e o câncer de } \\
\text { mama. }\end{array}$ \\
\hline $\begin{array}{l}\text { (Dickerman } \\
\text { et al., 2016) }\end{array}$ & 11.370 & $\begin{array}{l}\text { Estudo de } \\
\text { coorte } \\
\text { prospectivo }\end{array}$ & $\begin{array}{c}\text { Câncer de } \\
\text { próstata }\end{array}$ & $\begin{array}{l}\text { Gêmeos na } \\
\text { Finlândia }\end{array}$ & $\begin{array}{l}\text { Investigar a associação do } \\
\text { trabalho noturno entre os } \\
\text { parâmetros relacionados ao } \\
\text { sono, ritmos circadianos e } \\
\text { ao risco de câncer de } \\
\text { próstata e mortalidade em } \\
\text { gêmeos. }\end{array}$ & $\begin{array}{l}\text { Trabalhos noturnos tiveram um } \\
\text { risco significativamente } \\
\text { aumentado para câncer de } \\
\text { próstata em relação aos trabalhos } \\
\text { matinais. }\end{array}$ \\
\hline $\begin{array}{l}\text { (Cordina- } \\
\text { duverger et } \\
\text { al., 2016) }\end{array}$ & 2.292 & $\begin{array}{c}\text { Estudo de } \\
\text { caso controle }\end{array}$ & $\begin{array}{c}\text { Câncer de } \\
\text { mama }\end{array}$ & $\begin{array}{c}\text { Trabalhadoras } \\
\text { noturnas na } \\
\text { França }\end{array}$ & $\begin{array}{c}\text { Identificar a relação entre } \\
\text { trabalho noturno e câncer } \\
\text { de mama. }\end{array}$ & $\begin{array}{l}\text { Trabalhar a noite pode aumentar } \\
\text { o risco de câncer de mama, } \\
\text { particularmente entre mulheres na } \\
\text { pré-menopausa. }\end{array}$ \\
\hline $\begin{array}{l}\text { (Fang et al., } \\
\text { 2015) }\end{array}$ & 15 & $\begin{array}{c}\text { Estudo } \\
\text { experimental }\end{array}$ & $\begin{array}{l}\text { Câncer de } \\
\text { mama e } \\
\text { próstata }\end{array}$ & $\begin{array}{l}\text { Residentes e } \\
\text { estagiários de } \\
\text { Medicina nos } \\
\text { Estados } \\
\text { Unidos }\end{array}$ & $\begin{array}{l}\text { Avaliar alterações na } \\
\text { expressão de CG e CCG no } \\
\text { sangue total de } \\
\text { trabalhadores por turno } \\
\text { com ruptura do ritmo } \\
\text { circadiano e a relação com } \\
\text { câncer de próstata e de } \\
\text { mama. }\end{array}$ & $\begin{array}{l}\text { Foi observada uma expressão } \\
\text { diferenciada do gene } P E R 2 \text { em } \\
\text { trabalhadores por turno. }\end{array}$ \\
\hline $\begin{array}{l}\text { (Hammer et } \\
\text { al., 2015) }\end{array}$ & 27.828 & $\begin{array}{l}\text { Estudo de } \\
\text { coorte }\end{array}$ & $\begin{array}{l}\text { Câncer de } \\
\text { próstata }\end{array}$ & $\begin{array}{c}\text { Trabalhadores } \\
\text { industriais na } \\
\text { Alemanha }\end{array}$ & $\begin{array}{l}\text { Buscar evidencias sobre o } \\
\text { efeito cancerígeno em } \\
\text { trabalho noturno e } \\
\text { associação com o câncer de }\end{array}$ & $\begin{array}{l}\text { Os trabalhadores noturnos não } \\
\text { apresentaram uma taxa de risco } \\
\text { elevada para câncer de próstata } \\
\text { em comparação com os }\end{array}$ \\
\hline
\end{tabular}


Research, Society and Development, v. 10, n. 12, e150101220239, 2021

(CC BY 4.0) | ISSN 2525-3409 | DOI: http://dx.doi.org/10.33448/rsd-v10i12.20239

\begin{tabular}{|c|c|c|c|c|c|c|}
\hline & & & & & próstata. & trabalhadores diurnos. \\
\hline $\begin{array}{l}\text { (Åkerstedt et } \\
\text { al. 2015) }\end{array}$ & 13.656 & $\begin{array}{l}\text { Estudo de } \\
\text { coorte }\end{array}$ & $\begin{array}{c}\text { Câncer de } \\
\text { mama }\end{array}$ & $\begin{array}{l}\text { Trabalhadoras } \\
\text { noturnas na } \\
\text { Suécia }\end{array}$ & $\begin{array}{l}\text { Buscar informações sobre } \\
\text { o número de anos de } \\
\text { trabalho noturno e o risco } \\
\text { de câncer de mama. }\end{array}$ & $\begin{array}{l}\text { O trabalho noturno foi associado } \\
\text { com um risco aumentado de } \\
\text { câncer de mama em mulheres, } \\
\text { mas somente após exposição a } \\
\text { longo prazo. }\end{array}$ \\
\hline $\begin{array}{l}\text { (Wang et al., } \\
\text { 2015) }\end{array}$ & 1.454 & $\begin{array}{l}\text { Estudo de } \\
\text { caso controle }\end{array}$ & $\begin{array}{c}\text { Câncer de } \\
\text { mama }\end{array}$ & $\begin{array}{l}\text { Mulheres na } \\
\text { China }\end{array}$ & $\begin{array}{l}\text { Avaliar as associações } \\
\text { separadas e combinadas de } \\
\text { trabalho noturno, duração } \\
\text { do sono e cochilos diurnos } \\
\text { com risco de câncer de } \\
\text { mama na população } \\
\text { chinesa. }\end{array}$ & $\begin{array}{l}\text { O trabalho no turno da noite foi } \\
\text { associado a um risco aumentado } \\
\text { de câncer de mama. }\end{array}$ \\
\hline $\begin{array}{l}\text { (Papantoniou } \\
\text { et al., 2015) }\end{array}$ & 2.483 & $\begin{array}{c}\text { Estudo de } \\
\text { caso controle }\end{array}$ & $\begin{array}{l}\text { Câncer de } \\
\text { próstata }\end{array}$ & $\begin{array}{l}\text { Trabalhadores } \\
\text { noturno na } \\
\text { Espanha }\end{array}$ & $\begin{array}{l}\text { Avaliar o trabalho no turno } \\
\text { da noite em relação ao } \\
\text { câncer de próstata, levando } \\
\text { em consideração o } \\
\text { cronótipo e a gravidade da } \\
\text { doença. }\end{array}$ & $\begin{array}{l}\text { Foi encontrada uma associação } \\
\text { entre trabalho noturno e câncer de } \\
\text { próstata, particularmente para } \\
\text { tumores com pior prognóstico. }\end{array}$ \\
\hline $\begin{array}{l}\text { (Pham et al., } \\
\text { 2019) }\end{array}$ & 1.900 & $\begin{array}{c}\text { Estudo de } \\
\text { caso controle }\end{array}$ & $\begin{array}{c}\text { Câncer de } \\
\text { mama }\end{array}$ & $\begin{array}{l}\text { Mulheres na } \\
\text { Coréia }\end{array}$ & $\begin{array}{l}\text { Investigar o impacto dos } \\
\text { genes da via circadiana e } \\
\text { da melatonina, bem como } \\
\text { suas interações com o } \\
\text { trabalho noturno no risco } \\
\text { de câncer de mama em } \\
\text { mulheres coreanas. }\end{array}$ & $\begin{array}{c}\text { Os resultados apoiam um papel } \\
\text { putativo de vários loci em genes } \\
\text { circadianos e genes da biossíntese } \\
\text { de melatonina no } \\
\text { desenvolvimento de câncer de } \\
\text { mama. }\end{array}$ \\
\hline $\begin{array}{l}\text { (Jones et al., } \\
\text { 2019) }\end{array}$ & 102.869 & $\begin{array}{l}\text { Estudo de } \\
\text { coorte }\end{array}$ & $\begin{array}{c}\text { Câncer de } \\
\text { mama }\end{array}$ & $\begin{array}{l}\text { Mulheres do } \\
\text { Reino Unido }\end{array}$ & $\begin{array}{c}\text { Investigar possíveis } \\
\text { associações entre o câncer } \\
\text { de mama e o trabalho } \\
\text { noturno. }\end{array}$ & $\begin{array}{l}\text { Não foi encontrado evidências de } \\
\text { um aumento geral do risco de } \\
\text { câncer de mama para mulheres } \\
\text { que trabalhavam no turno da } \\
\text { noite. }\end{array}$ \\
\hline $\begin{array}{l}\text { (Carugno et } \\
\text { al., 2019) }\end{array}$ & 97 & $\begin{array}{l}\text { Estudo de } \\
\text { caso controle }\end{array}$ & $\begin{array}{l}\text { Câncer de } \\
\text { mama }\end{array}$ & $\begin{array}{l}\text { Enfermeiras } \\
\text { na Itália. }\end{array}$ & $\begin{array}{c}\text { Avaliar a associação entre } \\
\text { o trabalho e a metilação do } \\
\text { DNA dos genes } \\
\text { supressores de tumor de } \\
\text { mama. }\end{array}$ & $\begin{array}{c}\text { Foi encontrada uma associação } \\
\text { entre exposição prolongada ao } \\
\text { turno da noite e alterações } \\
\text { moleculares que podem estar } \\
\text { envolvidas em processos como } \\
\text { envelhecimento celular, } \\
\text { instabilidade genômica e } \\
\text { desenvolvimento de câncer. }\end{array}$ \\
\hline $\begin{array}{l}\text { (Pham et al., } \\
\text { 2019) }\end{array}$ & 3.442 & $\begin{array}{c}\text { Estudo de } \\
\text { caso controle }\end{array}$ & $\begin{array}{c}\text { Câncer de } \\
\text { mama }\end{array}$ & $\begin{array}{l}\text { Mulheres na } \\
\text { Coréia }\end{array}$ & $\begin{array}{l}\text { Associação entre trabalho } \\
\text { noturno e risco de câncer } \\
\text { de mama. }\end{array}$ & $\begin{array}{l}\text { Apresentou-se o risco elevado de } \\
\text { câncer de mama a longo prazo. }\end{array}$ \\
\hline $\begin{array}{l}\text { (De castro et } \\
\text { al., 2018) }\end{array}$ & 72 & $\begin{array}{c}\text { Estudo } \\
\text { experimental }\end{array}$ & $\begin{array}{c}\text { Câncer de } \\
\text { mama }\end{array}$ & $\begin{array}{c}\text { Mulheres } \\
\text { com câncer } \\
\text { de mama em } \\
\text { tratamento, } \\
\text { mulheres com } \\
\text { câncer de } \\
\text { mama sem } \\
\text { tratamento, } \\
\text { mulheres sem } \\
\text { câncer e } \\
\text { enfermeiras } \\
\text { que } \\
\text { trabalhavam } \\
\text { exclusivamen } \\
\text { te no turno da } \\
\text { noite no } \\
\text { Brasil }\end{array}$ & $\begin{array}{l}\text { Avaliar os níveis de } \\
\text { melatonina em mulheres } \\
\text { recentemente } \\
\text { diagnosticadas com câncer } \\
\text { de mama, mulheres em } \\
\text { quimioterapia adjuvante e } \\
\text { enfermeiras do turno da } \\
\text { noite, e compará-las com } \\
\text { mulheres saudáveis para } \\
\text { avaliar a relação desses } \\
\text { compostos com o risco de } \\
\text { câncer de mama. }\end{array}$ & $\begin{array}{l}\text { Mostraram que mulheres com } \\
\text { câncer de mama apresentaram } \\
\text { níveis mais baixos de melatonina } \\
\text { em comparação com as mulheres } \\
\text { do grupo controle, e ainda mais } \\
\text { baixas em enfermeiras do turno } \\
\text { da noite e em pacientes sob } \\
\text { quimioterapia adjuvante. }\end{array}$ \\
\hline
\end{tabular}




\begin{tabular}{|c|c|c|c|c|c|c|}
\hline $\begin{array}{l}\text { (Wendeu- } \\
\text { foyet et al., } \\
\text { 2018) }\end{array}$ & 1.693 & $\begin{array}{c}\text { Estudo de } \\
\text { caso controle }\end{array}$ & $\begin{array}{l}\text { Câncer de } \\
\text { próstata }\end{array}$ & $\begin{array}{c}\text { Homens na } \\
\text { França }\end{array}$ & $\begin{array}{c}\text { Investigar o papel do } \\
\text { trabalho noturno no câncer } \\
\text { de próstata. }\end{array}$ & $\begin{array}{l}\text { Uma longa duração de pelo } \\
\text { menos } 20 \text { anos de trabalho } \\
\text { noturno permanente foi associada } \\
\text { ao câncer de próstata agressivo. }\end{array}$ \\
\hline $\begin{array}{l}\text { (Garcia- } \\
\text { saenz et al., } \\
\text { 2018) }\end{array}$ & 4.106 & $\begin{array}{c}\text { Estudo de } \\
\text { caso controle }\end{array}$ & $\begin{array}{l}\text { Câncer de } \\
\text { mama e de } \\
\text { próstata }\end{array}$ & $\begin{array}{l}\text { Homens e } \\
\text { mulheres na } \\
\text { Espanha }\end{array}$ & $\begin{array}{l}\text { Avaliar a associação entre } \\
\text { exposição artificial à luz } \\
\text { noturna e risco de câncer } \\
\text { de mama e próstata. }\end{array}$ & $\begin{array}{l}\text { Tanto o câncer de próstata } \\
\text { quanto o de mama foram } \\
\text { associados à alta exposição } \\
\text { artificial à luz noturna. }\end{array}$ \\
\hline $\begin{array}{l}\text { (Fritschi et } \\
\text { al., 2018) }\end{array}$ & 6.440 & $\begin{array}{c}\text { Estudo de } \\
\text { caso controle }\end{array}$ & $\begin{array}{l}\text { Câncer de } \\
\text { mama }\end{array}$ & $\begin{array}{c}\text { Trabalhadoras } \\
\text { noturnas na } \\
\text { Austrália }\end{array}$ & $\begin{array}{l}\text { Testar a hipótese de que as } \\
\text { mulheres que trabalhavam } \\
\text { durante a noite teriam um } \\
\text { risco aumentado de câncer } \\
\text { de mama. }\end{array}$ & $\begin{array}{l}\text { Não foram encontrados resultados } \\
\text { suficientes que pudessem } \\
\text { comprovar a associação do } \\
\text { trabalho noturno com o câncer de } \\
\text { mama. }\end{array}$ \\
\hline $\begin{array}{l}\text { (Papantoniou } \\
\text { et al., 2016) }\end{array}$ & 3.486 & $\begin{array}{c}\text { Estudo de } \\
\text { caso controle }\end{array}$ & $\begin{array}{l}\text { Câncer de } \\
\text { mama }\end{array}$ & $\begin{array}{c}\text { Trabalhadoras } \\
\text { noturnas na } \\
\text { Espanha }\end{array}$ & $\begin{array}{l}\text { Investigar a associação do } \\
\text { trabalho noturno e o câncer } \\
\text { de mama em população na } \\
\text { Espanha. }\end{array}$ & $\begin{array}{l}\text { O trabalho noturno foi associado } \\
\text { a um risco câncer de mama mais } \\
\text { alto comparado a indivíduos } \\
\text { nunca envolvidos em trabalho } \\
\text { noturno. }\end{array}$ \\
\hline $\begin{array}{c}\text { (Li et al., } \\
\text { 2015) }\end{array}$ & 6489 & $\begin{array}{l}\text { Estudo de } \\
\text { coorte }\end{array}$ & $\begin{array}{l}\text { Câncer de } \\
\text { mama }\end{array}$ & $\begin{array}{l}\text { Mulheres na } \\
\text { china }\end{array}$ & $\begin{array}{c}\text { Investigar uma possível } \\
\text { associação entre o trabalho } \\
\text { noturno e o risco de câncer } \\
\text { de mama. }\end{array}$ & $\begin{array}{l}\text { Não foram encontradas } \\
\text { evidências significativas para } \\
\text { apoiar a hipótese de que o } \\
\text { trabalho noturno aumenta o risco } \\
\text { de câncer de mama. }\end{array}$ \\
\hline $\begin{array}{l}\text { (Son et al., } \\
\text { 2017) }\end{array}$ & 1193 & $\begin{array}{c}\text { Estudo } \\
\text { transversal }\end{array}$ & $\begin{array}{l}\text { Câncer de } \\
\text { mama }\end{array}$ & $\begin{array}{c}\text { Mulheres na } \\
\text { Coréia }\end{array}$ & $\begin{array}{l}\text { Examinar a associação } \\
\text { entre tipos de trabalho por } \\
\text { turnos e participação em } \\
\text { programas de rastreamento } \\
\text { do câncer de mama, } \\
\text { comparando as taxas de } \\
\text { participação entre } \\
\text { trabalhadores diurnos } \\
\text { regulares e trabalhadores } \\
\text { de turnos alternativos na } \\
\text { Coréia. }\end{array}$ & $\begin{array}{l}\text { Os resultados sugerem a } \\
\text { necessidade do desenvolvimento } \\
\text { de programas abrangentes de } \\
\text { prevenção do câncer de mama no } \\
\text { local de trabalho, considerando os } \\
\text { tipos de trabalho por turnos. }\end{array}$ \\
\hline $\begin{array}{c}\text { (Erdem et al., } \\
\text { 2017) }\end{array}$ & 558 & $\begin{array}{c}\text { Estudo de } \\
\text { caso controle }\end{array}$ & $\begin{array}{l}\text { Câncer de } \\
\text { mama }\end{array}$ & $\begin{array}{l}\text { Enfermeiras } \\
\text { da Noruega }\end{array}$ & $\begin{array}{c}\text { Avaliar se a regulação } \\
\text { epigenética de } C L O C K, \\
B M A L 1, C R Y 1 \text { e } P E R 1 \\
\text { pode contribuir para o } \\
\text { câncer de mama em } \\
\text { trabalhadores noturnos. }\end{array}$ & $\begin{array}{c}\text { Foi sugerido que o trabalho por } \\
\text { turnos esteja associado ao risco } \\
\text { de câncer de mama, e a } \\
\text { interrupção circadiana em } \\
\text { trabalhadores por turnos é } \\
\text { considerada um dos mecanismos } \\
\text { de aumento do risco de câncer. }\end{array}$ \\
\hline
\end{tabular}

Fonte: Autores.

\section{Discussão}

Nesta revisão foi buscada na literatura científica evidências da influência do trabalho rotativo no câncer de mama e câncer de próstata. Desde que o trabalho noturno foi classificado como potencialmente cancerígeno, e sugerido como fator de risco para câncer de mama e câncer de próstata, tem aumentado o número de pesquisas sobre seu efeito na saúde. $\mathrm{O}$ trabalho por turnos está associado a efeitos negativos à saúde, incluindo diversos fatores e com maior tendência a obesidade, sedentarismo e uma maior associação ao uso de tabaco, álcool e outras drogas que predispõe o desenvolvimento do câncer. De acordo com os artigos estudados nesta revisão, tem sido feito esforços para explorar outros fatores de risco para este tipo de câncer, incluindo fatores ocupacionais ou ambientais (Buchvold et al., 2015). 
No presente estudo foram utilizados estudos coorte, estudos de caso controle, estudos transversais e estudos experimentais, onde mostrou-se uma relação entre o trabalho noturno e câncer de mama e próstata em diversas áreas de trabalho e grupos ocupacionais, como, por exemplo, enfermeiros e estagiários residentes hospitalares (Carugno et al., 2019; de castro et al., 2018; Erdem et al., 2017; Samulin et al., 2017; Schernhammer et al., 2017). No entanto, 4 desses estudos mostraram resultados discordantes aos demais, constando que não foram encontradas evidências estatisticamente significantes entre o trabalho noturno e o câncer de mama (Fritschi et al., 2018; Jones et al., 2019; Li et al., 2015; PHAM et al., 2019; ). Assim como outros 2 trabalhos discorrem não ter sido comprovado relação entre trabalho noturno e câncer de próstata (Åkerstedt et al., 2017; Hammer et al., 2015).

Foi avaliada a relação entre o trabalho noturno por turno que envolve perturbações circadianas e o câncer de mama, onde os autores discutem explicações para essa relação. Em um dos estudos foi sustentado à ideia que a melatonina produz um potencial efeito anticâncer, e que a desregulação do ritmo circadiano diminui sua produção, o que inibe sua função de supressão tumoral em diversos tecidos, incluindo mama. Assim, níveis mais baixos de melatonina estão relacionados ao aumento do risco de desenvolver câncer mama. Também foi observada uma baixa quantidade de melatonina em pacientes já acometidos com a patologia. $\mathrm{O}$ estudo ainda sugere uma suplementação à base de melatonina como medida preventiva contra $\mathrm{o}$ câncer de mama em trabalhadoras noturnas (De castro et al., 2018; Garcia-saenz et al., 2018).

A exposição ao trabalho noturno por longos períodos acabam por diminuir a síntese de melatonina, que está diretamente relacionada à expressão de genes circadianos. Esses genes circadianos, também conhecidos como genes do relógio são uma família de genes que regulam o ritmo circadiano. Assim, quando há alterações polimórficas ou de expressão nesses genes, também altera o ritmo circadiano e a homeostase corporal (Pham et al., 2019). Existem alguns polimorfismos genéticos ligados ao ritmo circadiano que podem favorecer algumas/ doenças como síndrome metabólica e câncer. Portanto, trabalhadores por turno que já estão em uma rotina onde possam favorecer o surgimento do câncer de mama e que tenham esses polimorfismos, terão um aumento significativo de vir a ter essa doença (Morales-santana et al., 2019). Com isso, uma futura abordagem para promoção de saúde de trabalhadores seria um cuidado maior com pessoas com predisposição genética a ter disfunção circadiana.

Pesquisas afirmam que outro possível causador do câncer de mama relacionado ao trabalho noturno é o encurtamento dos telômeros, que são afetados devido a carga horária excessiva de trabalho noturno que pode causar interrupções nos ritmos circadianos e nos padrões de sono. Essa carga excessiva está atribuída a turnos consecutivos, influenciando demasiadamente este processo (Samulin et al., 2017). Desse modo, é possível dizer que a redução do cumprimento dos telômeros pode ser um contribuinte no surgimento do câncer de mama em trabalhadores com carga excessiva de trabalho noturno sequencial em que não haja um intervalo de tempo que estabeleça um período de descanso. Esses dados denotam uma preocupação quanto ao fator responsável pelo encurtamento dos telômeros, quando associam esse processo como responsável ou possível contribuinte para o surgimento do câncer de mama entre mulheres que trabalham em extensos horários noturnos (Jafri et al., 2016).

No estudo de Vistisen et al. (2017) foi relatado que o trabalho noturno mostrou uma associação significativa com o câncer de mama após 10 anos de exposição, porém seus achados são divergentes com os achados de outro estudo, onde foi realizada uma análise detalhada do trabalho no turno da noite e do risco de câncer de mama, analisando riscos relativos em relação a vários aspectos de trabalho noturno nos últimos 10 anos, e a maioria dos achados não foram estatisticamente significantes para o período (Jones et al., 2019). Por outro lado, Åkerstedt et al. (2015) defendem que o trabalho noturno tem efeitos significativos para o surgimento de câncer de mama após 20 anos de exposição. Portanto, tendo por base os artigos estudados, apesar dos seus resultados divergentes, observa-se que o trabalho noturno tem uma influência no câncer de mama a longo prazo. Isso pode ter implicação em medidas de saúde pública que evitem a longa exposição de trabalhadores a jornadas de trabalho noturno. 
Em relação ao câncer de mama, também é evidenciado que o trabalho noturno que envolva perturbações circadianas, acaba por ocasionar um desequilíbrio hormonal, todavia esses estudos nem sempre trazem uma abordagem detalhada de forma clara (Dickerman et al., 2016). Sabe-se que alguns desses hormônios estão intimamente relacionados ao câncer de mama e câncer de próstata, como apontam Dickerman et al. (2016) em um estudo de coorte onde relata que o trabalho noturno pode aumentar o risco de câncer de próstata através de mecanismos de redução e desregulação do sono, provocando interrupção circadiana e supressão da secreção de melatonina induzida pela luz. Estudos sugerem que exposição a longo prazo a baixos níveis de melatonina pode estar relacionada a um maior risco de câncer de próstata e câncer de mama uma vez que são canceres dependentes de hormônios e a melatonina tem atividade sobre o metabolismo hormonal (Garcia-saenz et al., 2018).

Em relação ao câncer de próstata, foi observado um risco significativamente aumentado entre os tipos de trabalho noturnos que envolvem perturbações circadianas (Behrens et al., 2017). Por outro lado, Åkerstedt et al. (2017) e Hammer et al. (2015) relatam em estudos de coorte, que não foi encontrada associação estatisticamente significativa entre a quantidade de trabalho noturno e o câncer de próstata. No entanto, vale ressaltar a importância de estudos mais aprofundados sobre as possíveis associações entre trabalho noturno e tal patologia, pois há dados conflitantes.

Foi observado em um estudo de caso controle a associação entre o trabalho por turno e o aumento de risco de câncer de próstata, particularmente para tumores de alto risco com pior prognóstico e maior taxa de mortalidade (Papantoniou et al., 2015). O estudo citou ainda que já foi evidenciado uma relação entre o trabalho por turno e níveis elevados de antígenos prostático específico (PSA) (Flynn-evans et al., 2014). Sugere-se que altos níveis desse antígeno no sangue apresenta um maior risco de câncer de próstata. Assim, são inúmeras as evidências da relação entre trabalho noturno tanto com o câncer de próstata, assim como com o câncer de mama, porém necessita-se de pesquisas mais consistentes para que possa provar de forma mais conclusiva essa relação.

\section{Considerações Finais}

O trabalho por turno que envolve perturbações no ritmo circadiano foi associado ao câncer de mama e câncer de próstata na maioria dos estudos encontrados. No entanto, o número de estudos relacionado a influência do trabalho noturno e o câncer de próstata foi bem menor, o que torna necessário que mais pesquisas sejam desenvolvidas a respeito do tema. Os dois tipos de cânceres foram associados à interrupção circadiana e a exposição à luz artificial noturna durante o trabalho. A taxa de risco apresentou-se fortemente elevada entre trabalhadores por turno empregados a longo prazo, mostrando a relevância da exposição a longo prazo. Foi evidenciada uma redução nos níveis de melatonina em trabalhadores noturnos, assim como também foi observado essa redução em pacientes com câncer de mama. Sugere-se que baixos níveis desse hormônio esteja significativamente associado ao câncer de mama e próstata. Portanto, acredita-se que a cronoterapia, como uma suplementação a base de melatonina em trabalhadores noturnos, pode ser uma medida preventiva contra câncer de mama e próstata.

Além disso, outro fator que foi associado ao câncer de mama é o encurtamento dos telômeros. Esse, por sua vez encontra-se relacionado a carga horária excessiva de trabalho noturno que pode causar interrupções nos ritmos circadianos e nos padrões de sono. No entanto, alguns estudos discorrem não ter sido encontrado relação significativa entre o trabalho noturno e o câncer de mama e próstata. Diante do exposto, conclui-se a importância de que novas pesquisas devem ser realizadas para que essa relação seja mais explorada. Além disso, mostra como podem ser importantes medidas para monitorar alterações fisiológicas e risco de exposição aos trabalhadores por turno, a fim de promover a saúde nesse grupo de risco.

\section{Referências}

Åkerstedt, T. et al. (2015). Night Work and Breast Cancer in Women: A Swedish Cohort Study. Bmj Open, V. 5, N. 4, P. E008127. http://dx.doi.org/10.1136/bmjopen-2015-008127. 
Åkerstedt, T. et al. (2017). Night Work and Prostate Cancer in Men: A Swedish Prospective Cohort Study. Bmj Open, V. 7, N. 6, P. E015751, http://dx.doi.org/10.1136/bmjopen-2016-015751.

Behrens, T. et al. (2017). Shift Work and The Incidence of Prostate Cancer: A 10-Year Follow-Up of A German Population-Based Cohort Study. Scandinavian Journal of Work, Environment \& Health, V. 43, N. 6, P. 560-568, http://dx.doi.org/10.5271/sjweh.3666.

Carugno, M. et al. (2019). Night Shift Work, Dna Methylation and Telomere Length: An Investigation on Hospital Female Nurses. International Journal Of Environmental Research And Public Health, V. 16, N. 13, P. 2292, https://doi.org/10.3390/ijerph16132292.

Cordina-Duverger, E. et al. (2016). Night Work and Breast Cancer Risk Defined by Human Epidermal Growth Factor Receptor-2 (Her2) And Hormone Receptor Status: A Population-Based Case-Control Study in France. Chronobiology International, V. 33, N. 6, P. 783-787, https://doi.org/10.3109/07420528.2016.1167709.

Castro, T. B. et al. (2018). Evaluation Of Melatonin and Afmk Levels in Women with Breast Cancer. Endocrine, V. 62, N. 1, P. 242-249, http://doi.org/10.1007/s12020-018-1624-2.

Dickerman, B. A. et al. (2016). Sleep Disruption, Chronotype, Shift Work, And Prostate Cancer Risk and Mortality: A 30-Year Prospective Cohort Study Of Finnish Twins. Cancer Causes \& Control, V. 27, N. 11, P. 1361-1370, http://doi.org/10.1007/s10552-016-0815-5.

Erdem, J. S. et al (2017). Mechanisms Of Breast Cancer in Shift Workers: Dna Methylation in Five Core Circadian Genes In Nurses Working Night Shifts. Journal Of Cancer, V. 8, N. 15, P. 2876, http://doi.org/10.7150/jca.21064.

Fang, M. Z. et al. (2015). Sleep Interruption Associated with House Staff Work Schedules Alters Circadian Gene Expression. Sleep Medicine, V. 16, N. 11, P. 1388-1394, https://doi.org/10.1016/j.sleep.2015.06.011.

Flynn-Evans, E. E. et al. (2014). Shiftwork And Prostate-Specific Antigen in The National Health And Nutrition Examination Survey. Journal Of The National Cancer Institute, V. 105, N. 17, P. 1292-1297, https://doi.org/10.1093/jnci/djt169.

Fritschi, L. et al. (2018). Shift Work That Involves Circadian Disruption and Breast Cancer: A First Application Of Chronobiological Theory And The Consequent Challenges. Occup Environ Med, V. 75, N. 3, P. 231-234, http://dx.doi.org/10.1136/oemed-2017-104441.

Garcia-Saenz, A. et al. (2018). Evaluating The Association Between Artificial Light-At-Night Exposure and Breast and Prostate Cancer Risk In Spain (MccSpain Study). Environmental Health Perspectives, V. 126, N. 4, P. 047011, https://doi.org/10.1289/EHP1837.

Hammer, G. P. et al. (2015). Shift Work and Prostate Cancer Incidence in Industrial Workers: A Historical Cohort Study In A German Chemical Company. Deutsches Ärzteblatt International, V. 112, N. 27-28, P. 463, https://doi.org/10.3238/arztebl.2015.0463.

Jafri, M. A. et al. (2016). Roles Of Telomeres and Telomerase in Cancer, And Advances In Telomerase-Targeted Therapies. Genome Medicine, V. 8, N. 1, P. 69, https://doi.org/10.1186/s13073-016-0324-x.

Jones, M. E. et al. (2019). Night Shift Work and Risk of Breast Cancer In Women: The Generations Study Cohort. British Journal of Cancer, P. 1, https://doi.org/s41416-019-0485-7.

Li, W. et al. (2015). Shift Work and Breast Cancer Among Women Textile Workers In Shanghai, China. Cancer Causes \& Control, V. 26, N. 1, P. 143-150, https://doi.org/10.1007/s10552-014-0493-0.

Morales-Santana, S. et al. (2019). An Overview of The Polymorphisms of Circadian Genes Associated With Endocrine Cancer. Frontiers In Endocrinology, V. 10, P. 104, https://doi.org/10.3389/fendo.2019.00104.

Papantoniou, K. et al. (20116). Breast Cancer Risk and Night Shift Work In A Case-Control Study In A Spanish Population. European Journal Of Epidemiology, V. 31, N. 9, P. 867-878, https://doi.org/10.1007/s10654-015-0073-y.

Papantoniou, K. et al. (2015). Night Shift Work, Chronotype and Prostate Cancer Risk In The Mcc-S Pain Case-Control Study. International Journal Of Cancer, V. 137, N. 5, P. 1147-1157, https://doi.org/10.1002/ijc.29400.

Pham, T. T. et al. (2019). Night-Shift Work and Risk of Breast Cancer In Korean Women. Clinical Epidemiology, V. 11, P. 743, https://doi.org/ 10.2147/CLEP.S199521.

Pham, T. T. et al. (2019). Night-Shift Work, Circadian and Melatonin Pathway Related Genes And Their Interaction On Breast Cancer Risk: Evidence From A Case-Control Study In Korean Women. Scientific Reports, V. 9, N. 1, P. 1-9, https://doi.org/s41598-019-47480-2.

Samulin, E. J. et al. (2017). Mechanisms Of Breast Cancer Risk in Shift Workers: Association Of Telomere Shortening With The Duration And Intensity Of Night Work. Cancer Medicine, V. 6, N. 8, P. 1988-1997, https://doi.org/10.1002/cam4.1135.

Son, H. Kang, Y. (2017). Breast Cancer Screening Among Shift Workers: A Nationwide Population-Based Survey In Korea. International Journal Of Occupational And Environmental Health, V. 23, N. 2, P. 94-97, https://doi.org/10.1080/10773525.2018.1425656.

Vistisen, H. T. et al. (2017). Short-Term Effects of Night Shift Work On Breast Cancer Risk: A Cohort Study Of Payroll Data. Scandinavian Journal Of Work, Environment \& Health, V. 43, N. 1, P. 59-67, https://doi.org/10.5271/sjweh.3603.

Wang, P. et al. (2015). Night-Shift Work, Sleep Duration, Daytime Napping, And Breast Cancer Risk. Sleep Medicine, V. 16, N. 4, P. 462-468, https://doi.org/10.1016/j.sleep.2014.11.017.

Wendeu, F. Méyomo, G et al. (2018). Night Work and Prostate Cancer Risk: Results From The Epicap Study. Occup Environ Med, V. 75, N. 8, P. 573-581, https://doi.org/10.1136/oemed-2018-105009. 